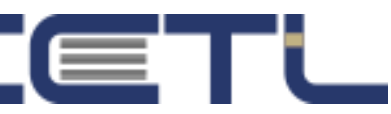

International Conference on Research in Education, Teaching and Learning

Paris, France| November 2 -4, 2018

\title{
The Impact of Differentiated Instruction in Flipped Classrooms on Students' Achievement
}

\author{
Abuhmaid, A. \\ Hashemite University/Faculty of Education
}

\begin{abstract}
The current study aimed at examining the effect of differentiated instruction in flipped learning classrooms on students' achievement. Increasingly, it is emphasized that students are seen as unique individuals who need to be treated accordingly. Thus, differentiated instruction has gained ground in teaching practices worldwide in order to enable teachers to take students' differences into account. However, in light of the current situation of Jordanian schools, implementing this method is impeded by the current situation in schools especially in terms of crowded classrooms and the overwhelmed teachers. Additionally, flipped learning is being promoted as an approach which can free class time which can be invested productively to improve the quality of teaching and learning. Thus, it was proposed that flipped learning can provide a fertile ground for implementing the differentiated instruction method. The study utilized a quasi-experimental research design. Two groups were selected for the conduct of the study. One experimental group and one control group were randomly assigned at AlNajah Secondary School in Zarqa, Jordan, and each group consisted of 25 female students. Both groups were taught in a differentiated instruction method, however, the experimental group was taught by the flipped learning approach while the control group was taught in a traditional setting. The results of the study showed significant differences at the level of $(\alpha=0.05)$ on the students' achievement test in Biology in favour of the experimental group which was taught in a differentiated instruction method by the flipped learning approach.
\end{abstract}

Keywords: Differentiated Instruction Flipped Learning, Teaching Methods, Jordan. 
